\title{
Condições Ambientais e de Saúde Pública da População do Bairro dos Eucaliptos, Moçâmedes (Angola)
}
Environmental and Public Health Conditions of the Population of the Eucaliptos Neighborhood, Moçâmedes (Angola)

Condiciones ambientales y de salud pública de la población del barrio Eucaliptos, Moçâmedes (Angola)

Aldino Miguel Francisco

Doutorando, UNESP, Brasil. aldino.francisco@unesp.br

Evelina Imaculada Zambi Graduada, UMN, Angola. Ivethzambi88@gmail.com

\author{
Celestina Vandaco Jorge Abílio \\ Graduada, UAN, Angola. \\ celvanda@hotmail.com
}




\title{
Revista Científica ANAP Brasil
}

\author{
ISSN 1984-3240 - Volume 14, número 34, 2021
}

\section{RESUMO}

A pesquisa aborda as condições de sanidade do meio ambiente e seus efeitos à saúde pública da população do Bairro dos Eucaliptos em Moçâmedes, Namibe (Angola). O problema foi estudado em função da constatação das péssimas condições de salubridade ambiental do bairro, e como objetivo apresentar as causas que ocasionaram a deficiente condições de saneamento básico do bairro dos Eucaliptos. A amostra constitui-se por elementos do centro de saúde dos Eucaliptos, escola Rui Duarte e população do bairro, que totalizaram 62 elementos. Aplicou-se inquéritos, pesquisa bibliográfica, registro fotográfico e observação cientifica, fez-se a sistematização e análise dos resultados do material qualitativo dos inquéritos com auxílio a estatística descritiva e porcentual. No que toca as deficiências de higiene e saneamento básico, os resultados apontaram na pouca cobertura da rede pública de água, o fornecimento não se faz em quantidade adequada, não atende a demanda, um número elevado de moradores faz o uso da água de cacimbas, irregular serviços de recolha de resíduos, formação de lixões, inexistência de esgoto sanitário, os moradores optam por fossas sépticas e defecção ao ar livre. As doenças causadas pela deficiência das condições de sanidade do meio registradas no Centro de Saúde Eucaliptos foram: a malária, febre tifoide, doenças diarreicas agudas, amebíase e infecções na pele. A malária registrou maior número de casos no período de 2012 à 2015. Com vista a melhorar a saúde pública do bairro, torna-se necessária a implementação do sistema de saneamento básico, programa de educação sanitária comunitária.

PALAVRAS-CHAVE: Saneamento básico. Meio ambiente. Saúde pública.

\section{ABSTRACT}

The research addresses the health conditions of the environment and its effects on the public health of the population of Bairro dos Eucaliptos in Moçâmedes, Namibe (Angola). The problem was studied based on the observation of the poor environmental health conditions of the neighborhood, and as an objective to present the causes that caused the deficient basic sanitation conditions in the Eucalyptus neighborhood. The sample consists of elements from the Eucalyptus health center, Rui Duarte school and the population of the neighborhood, which totaled 62 elements. Surveys, bibliographical research, photographic record and scientific observation were applied, and the results of the qualitative material of the surveys were systematized and analyzed with the aid of descriptive and percentage statistics. With regard to deficiencies in hygiene and basic sanitation, the results pointed to the poor coverage of the public water network, the supply is not made in adequate quantities, does not meet the demand, a high number of residents use water from wells, irregular waste collection services, formation of landfills, lack of sanitary sewage, residents opt for septic tanks and open defecation. Diseases caused by poor environmental health conditions registered at the Eucalyptus Health Center were: malaria, typhoid fever, acute diarrheal diseases, amoebiasis and skin infections. Malaria recorded the highest number of cases in the period 2012 to 2015. In order to improve public health in the neighborhood, it is necessary to implement a basic sanitation system, a community health education program. KEYWORDS: Basic sanitation. Environment. Public health.

\section{RESUMEN}

La investigación aborda las condiciones de salud del medio ambiente y sus efectos en la salud pública de la población del Bairro dos Eucaliptos en Moçâmedes, Namibe (Angola). El problema se estudió a partir de la observación de las malas condiciones de salud ambiental del barrio, y como objetivo presentar las causas que originaron las deficientes condiciones de saneamiento básico en el barrio Eucalyptus. La muestra está formada por elementos del centro de salud Eucalyptus, la escuela Rui Duarte y la población del barrio, que totalizó 62 elementos. Se aplicaron encuestas, investigación bibliográfica, registro fotográfico y observación científica, y se sistematizaron y analizaron los resultados del material cualitativo de las encuestas con ayuda de estadística descriptiva y porcentual. Con respecto a las deficiencias en higiene y saneamiento básico, los resultados apuntan a la mala cobertura de la red pública de agua, el suministro no se realiza en cantidades adecuadas, no se atiende la demanda, un alto número de pobladores utilizan agua de pozo, desperdicio irregular servicios de recolección, formación de rellenos sanitarios, falta de alcantarillado sanitario, los vecinos optan por fosas sépticas y defecación al aire libre. Las enfermedades causadas por malas condiciones de salud ambiental registradas en el Centro de Salud de Eucalyptus fueron: malaria, fiebre tifoidea, enfermedades diarreicas agudas, amebiasis e infecciones cutáneas. La malaria registró el mayor número de casos en el período 2012 a 2015. Para mejorar la salud pública en el barrio es necesario implementar un sistema de saneamiento básico, un programa comunitario de educación en salud.

PALABRAS CLAVE: Saneamiento básico. Medio ambiente. Salud pública. 


\section{Revista Científica ANAP Brasil}

ISSN 1984-3240 - Volume 14, número 34, 2021

\section{INTRODUÇÃO}

Os problemas de saúde pública e de poluição do meio ambiente obrigaram a humanidade a encontrar soluções de saneamento para a coleta e o tratamento dos esgotos, para o abastecimento de água segura para o consumo humano, para a coleta e o tratamento dos resíduos sólidos e para a drenagem das águas de chuva (RIBEIRO; ROOKE, 2010, p. 7).

Para GALVÃO JUNIOR (2009, p. 549) a saúde das pessoas influência diretamente o desenvolvimento de um local, tendo em vista que a participação do indivíduo na atividade económica e social depende de uma vida saudável, para tanto, é fundamental o acesso ao saneamento básico, assim como à moradia, à saúde e à educação. Segundo MOTA (2005), as atividades de saneamento integram as ações de saúde pública, pois visam à saúde da população, no sentido mais amplo.

Com base no decreto presidencial n. $196 / 12$ de 30 Agosto, dentre as várias responsabilidades da administração municipal, é também sua responsabilidade: gerir a organização e manutenção dos serviços públicos básicos como por exemplo a colecta de lixo; identificar e propor soluções para os problemas quotidianos da comunidade.

No que tange ao saneamento básico, no continente Africano, a situação é preocupante, sendo que na África subsaariana em 2011, apenas 30\% de população tinha instalações de saneamento melhorados, comparado com a África do Norte, no mesmo ano, contava com $90 \%$ de população que utiliza instalações de saneamento melhorados (JACINTO, 2012).

A infraestrutura sanitária deficiente desempenha uma interface com a situação de saúde e com as condições de vida das populações dos países em desenvolvimento, onde as doenças infecciosas continuam sendo um importante causa de morbidade e mortalidade (TEIXEIRA et. al., 2014, p. 89). A prevalência destas doenças constitui um forte indicativo de fragilidade dos sistemas públicos de saneamento.

\subsection{Situação problemática}

Para JACINTO (2012, p. 44), o défice no saneamento básico provoca danos à saúde pública e perda de dignidade para todos os que são afetados. Por causa deste défice, entre 13 de fevereiro de 2006 e 9 de maio de 2007, Angola registou um surto de cólera. De acordo com a OMS, nesse período, foram relatados 82204 casos de que resultaram em 3092 mortes. O pico do surto ocorreu no final de abril, em que se registou uma incidência diária de 950 casos. Para além da cólera, as diarreias agudas e a malária são a causa principal de mortalidade, sobretudo, em crianças menores de cinco anos, originada pela falta ou insuficiência de saneamento de águas e dos resíduos sólidos não tratados, transformando-os em focos de contaminação.

Segundo os resultados definitivos do recenseamento geral da população e da habitação em Angola, o lixo é deitado ao ar livre por 59\% dos agregados familiares residentes nas Áreas urbanas e 87\% dos residentes nas áreas rurais (Instituto Nacional de Estatística, 2014).

Para RIBEIRO; ROOKE (2010) a oferta do saneamento associa sistemas constituídos por uma infraestrutura física e uma estrutura educacional, legal e institucional, que abrange os seguintes serviços: 


\title{
Revista Científica ANAP Brasil
}

ISSN 1984-3240 - Volume 14, número 34, 2021

\begin{abstract}
abastecimento de água às populações de qualidade; acondicionamento, coleta, transporte e destino final dos resíduos sólidos; coleta, tratamento e disposição segura de águas residuais; coleta de águas pluviais; controle de vectores de doenças transmissíveis; saneamento da habitação, dos locais de trabalho, de educação, de recreação e dos hospitais; Saneamento dos alimentos; saneamento dos meios de transportes; saneamento e planeamento territorial e controle da poluição ambiental - água, ar, solo, acústica e visual (RIBEIRO; ROOKE, 2010, p. 1).
\end{abstract}

A saúde humana depende dos serviços de saneamento básico como fatores determinantes as relações entre o meio ambiente e a saúde. As doenças causadas pelos problemas da falta de saneamento básico atingem especialmente, a população mais carente (CARVALHO; ADOLFO, 2012, p. 8). As melhorias do meio ambiente determinaram a redução das taxas de doenças diarreicas e no controle das epidemias de tifo e cólera na Europa e América do Norte entre 1860 e 1920. Para (RIBEIRO; ROOKE, 2010) água contaminada pode prejudicar a saúde das pessoas.

\subsection{Justificação da pesquisa}

Segundo JACINTO (2012, p. 42), a situação do saneamento básico em Angola é extremamente preocupante. $\mathrm{O}$ balanço dos dados apresentados pelo Inquérito de Indicadores Básicos de Bem-Estar (2005-2006), mostra que menos de um quarto da população nacional possui uma sanita ligada a um sistema de esgotos. O plano estratégico nacional enfrenta dificuldades financeiros para o cumprimento dos objetivos de saneamento.

O saneamento básico é assegurado pelos Serviços Comunitários afeto a Administração Municipal de Moçâmedes. Nas zonas periféricas o saneamento é ainda deficiente, embora existam alguns contentores públicos de deposito de lixo. É possível encontrar focos de lixo em diferentes áreas. O município em 2012 produziu aproximadamente $1.582 .018 .550 \mathrm{Kg}$ de lixo. Neste ano as três captações de água (Benfica, Boa Vista e Kussi) já se demonstravam insuficientes, principalmente para abastecer a periferia.

A problemática da limitação da cobertura do sistema de esgotos, inexistência de drenagem de água pluviais, uso de latrinas com fossas sépticas, uso de água de poços, fraca coleta de resíduos, existência de lixão e o registro de doenças infectocontagiosas como febre tifoide, cólera, malária, são situações que se observam na região em estudo (bairro dos Eucaliptos).

\subsection{Objetivos}

O objetivo da pesquisa visa abordar as condições de sanidade do meio ambiente e seus efeitos à saúde pública da população do Bairro dos Eucaliptos em Moçâmedes. O diagnóstico precoce permitirá eliminar as fontes das doenças ocasionadas pelo défice de higiene e saneamento por intermédio de propostas e medidas de preventivas de saúde pública. 


\section{MATERIAL E MÉTODOS}

Tomando por base a afirmação de DIEHL e TATIM (2004), de que "a pesquisa se constitui num procedimento racional e sistemático, cujo objetivo é proporcionar respostas aos problemas propostos", nesta seção se apresenta a estratégia metodológica utilizada na pesquisa.

\subsection{Procedimento metodológico}

Tratou-se de um estudo transversal, desenvolvido entre agosto de 2016 à fevereiro de 2017. A particularidade de um estudo transversal é a de estudar um fenômeno que ocorre num dado momento. Para a sua realização recorreu-se aos artigos científicos, teses, dissertações e livros de especialidade, para o enquadramento lógico, sistemático e estrutural, fez-se a observação e levantamento fotográfico para constatação das condições deposição dos resíduos, rede de esgoto, abastecimento de água. Os instrumentos de recolha de informação consistiram em entrevistas, inquérito por questionário com perguntas mistas. A utilização do inquérito serviu para perceber as condições e a influência do saneamento básico na saúde dos habitantes.

A amostra foi de 62 elementos distribuída em: 20 moradores próximo ao Centro de Saúde Eucaliptos, que corresponde 0,14\% da população abrangida; 1 Diretor do Centro de Saúde Eucaliptos, que corresponde 0,86\% da população abrangida; 20 Alunos da 6a classe da Escola do Ensino Primário $\mathrm{N}^{\circ} 61 \mathrm{~N}$ Ruy Duarte de Carvalho, que corresponde $3,82 \%$ da população abrangida; 20 Alunos da 9a classe da Escola do Ensino Secundário do I Ciclo $N^{\circ}$ 61N Ruy Duarte de Carvalho, que corresponde 3,38\% da população abrangida; 1 Diretor da Escola do Ensino Primário e Secundário do I Ciclo $\mathrm{N}^{\circ} 61 \mathrm{~N}$ Ruy Duarte de Carvalho, que corresponde 1,14\% da população abrangida (Tabela 1).

Tabela 1 - Amostra das pessoas abrangidas pela pesquisa.

\begin{tabular}{|c|c|c|}
\hline Designação & Estratificação da amostra & Total \\
\hline Moradores próximo ao Centro de Saúde Eucaliptos & 20 & \\
\hline Diretor do Centro de Saúde Eucaliptos & 1 & \multirow{2}{*}{62} \\
\hline Alunos da 6a classe da Escola Ruy Duarte de Carvalho & 20 & \\
\hline Alunos da 9a classe da Escola Ruy Duarte de Carvalho & 20 & \\
\hline Diretor da Escola Ruy Duarte de Carvalho & 1 & \\
\hline
\end{tabular}

Fonte: AUTORES, (2016).

Os participantes foram sujeitos informados dos objetivos da pesquisa e de consentimento livres. Observou-se as orientações relativas às investigações em seres humanos, evitando qualquer tipo de dano físico ou moral da CIOMS-2002 (Council for International Organizations for Medical Sciences). Foi autorizado pelo Departamento de Engenharia do Ambiente do Instituto Superior Politécnico do Namibe, em 2016.

\subsection{Caraterização da área de estudo}




\section{Revista Científica ANAP Brasil}

ISSN 1984-3240 - Volume 14, número 34, 2021

O Bairro Eucaliptos localiza-se na zona central da cidade de Moçâmedes, sendo um dos bairros mais antigos da cidade (Figura 1). O mesmo possui uma população estimada em 14.300 habitantes e conta com 2.860 famílias provenientes de diferentes localidades do país. Uma das principais características do bairro é a ocupação desordenada do espaço urbano. $O$ trabalho foi realizado nas imediações do Centro de Saúde dos Eucaliptos, situado no Bairro Eucaliptos, município de Moçâmedes, província do Namibe, no Sudeste da República de Angola, no paralelo 15 entre $15^{\circ} 10^{\prime} 68^{\prime \prime}$ - S (Latitude) e 12 $09^{\prime} 73^{\prime \prime}$ - E (Longitude).

Figura 1 - Localização geográfica da área de trabalho

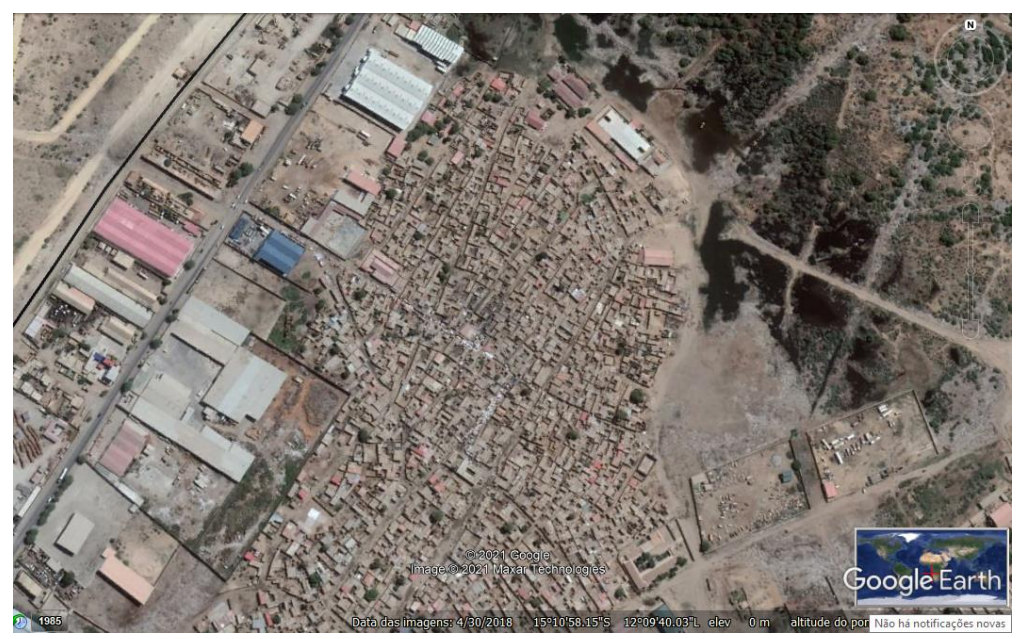

Fonte: AUTORES (2016)

\subsubsection{Caracterização do centro de saúde e da escola Ruy Duarte}

O Centro de Saúde Eucaliptos, foi inaugurada aos 17 de setembro de 2009, comporta um total de 116 funcionários, dos quais 62 enfermeiros e 54 funcionários administrativos. Atende diariamente um número estimativo de 64 pacientes com idades compreendidas entre os 0 aos 100 anos e possui a capacidade de internar 45 pacientes (Figura $2 \mathrm{~A}$ ).

A Escola do Ensino Primário e Secundário do I Ciclo N 61N "Ruy Duarte de Carvalho" alberga 1.115 alunos, sendo 523 do ensino primário e 592 do I ciclo, distribuídos em 3 turnos. A Escola possui 12 salas de aulas, o quadro do pessoal, comporta um total de 88 funcionários (Figura 2 B).

Figura 2 - Equipamentos sociais. A) Centro de Saúde Eucaliptos. B) Escola Ruy Duarte de Carvalho

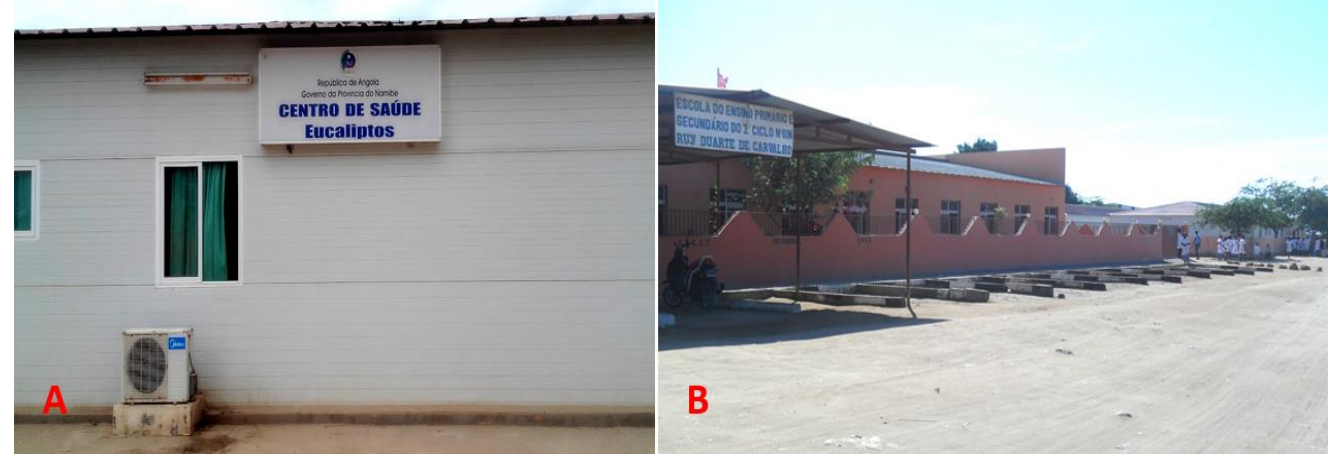

Fonte: AUTORES (2016) 


\section{Revista Científica ANAP Brasil}

ISSN 1984-3240 - Volume 14, número 34, 2021

\section{RESULTADOS}

Para melhor analise e tratamento dos dados, delimitou-se em três pontos focais: concretamente a população nas imediações do Centro de Saúde Eucaliptos, Centro de Saúde dos Eucaliptos e alunos da escola Ruy Duarte (Figura 3), num raio de 245 metros.

Figura 3 - Delimitação da área de estudo (polígono em vermelho)

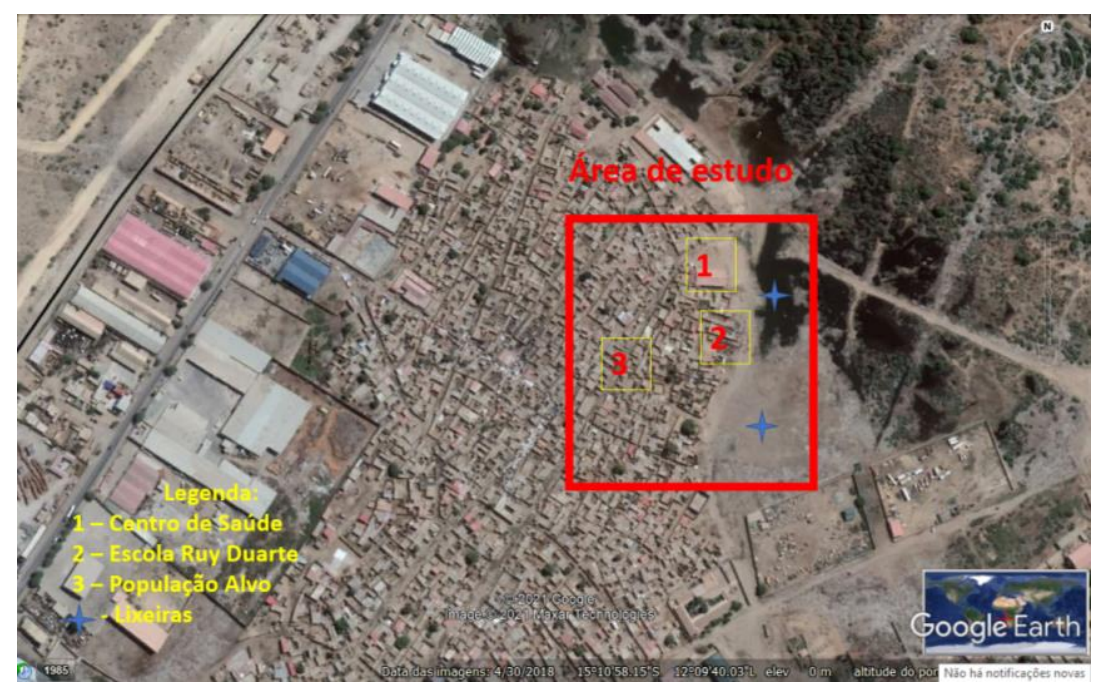

Fonte: google Earth, adaptado, AUTORES (2016)

\subsection{Resultados dos inquéritos aos moradores}

Quais são as deficiências de higiene e saneamento básico que a área apresenta? R: neste quesito os moradores apontaram a pouca cobertura no abastecimento de água, falta de serviços de recolha de lixo, fornecimento de água potável não se faz em quantidade adequada e use de água proveniente de cacimbas. A Figura 4 apresenta os resultados da questão, relação saneamento e saúde, 19 (95\%) moradores disseram que conhecem e 1 (5\%) morador disse que não conhecem a relação que saneamento básico desempenha na saúde da comunidade.

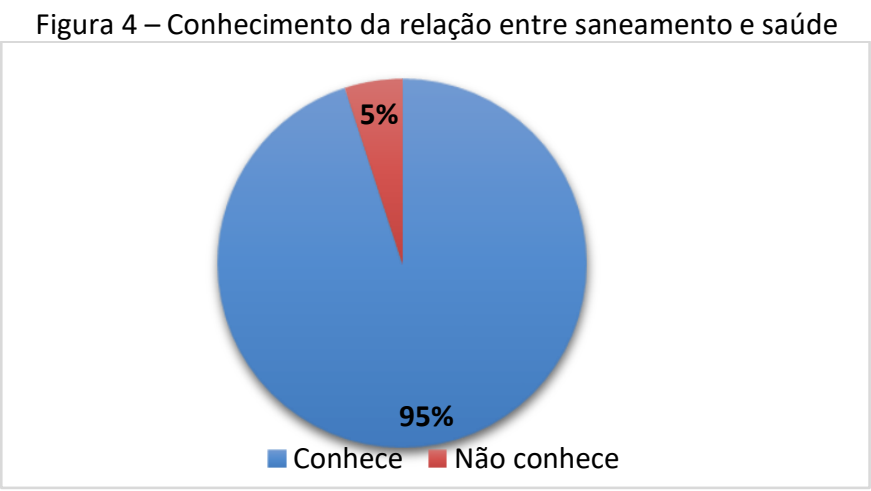

Fonte: AUTORES (2016) 


\section{Revista Científica ANAP Brasil}

ISSN 1984-3240 - Volume 14, número 34, 2021

Na sequência questionou-se se já contraiu alguma doença ligada as más condições de saneamento do meio, exemplo: febre tifoide, malária, cólera, diarreia, etc. 19 (95\%) moradores disseram que sim e 1 (5\%) morador disseram que não. (Figuras 5).

Figura 5 - Resultado da questão se já contraiu alguma doença ligada as más condições de saneamento

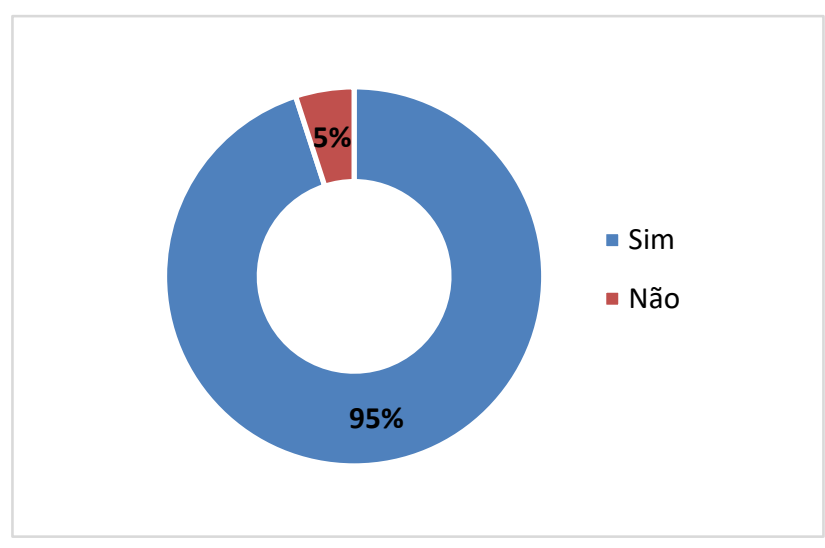

Fonte: AUTORES (2016)

A maioria dos inquiridos disseram que sim, conhecem as medidas de prevenção contra as doenças, sendo 19 (95\%) moradores disseram que sim apenas 1 (5\%) morador disse que não (Figura 6). De realçar que os inquiridos demonstraram conhecimentos e saberes sobre as medidas de prevenção, alguns afirmaram que combatem os transmissores de doenças fazendo a higienização das residências, das ruas e usam medicamentos contra insetos e roedores e frequentam os hospitais.

Figura 6 - Resultado da questão, conheces as medidas de prevenção dessas doenças

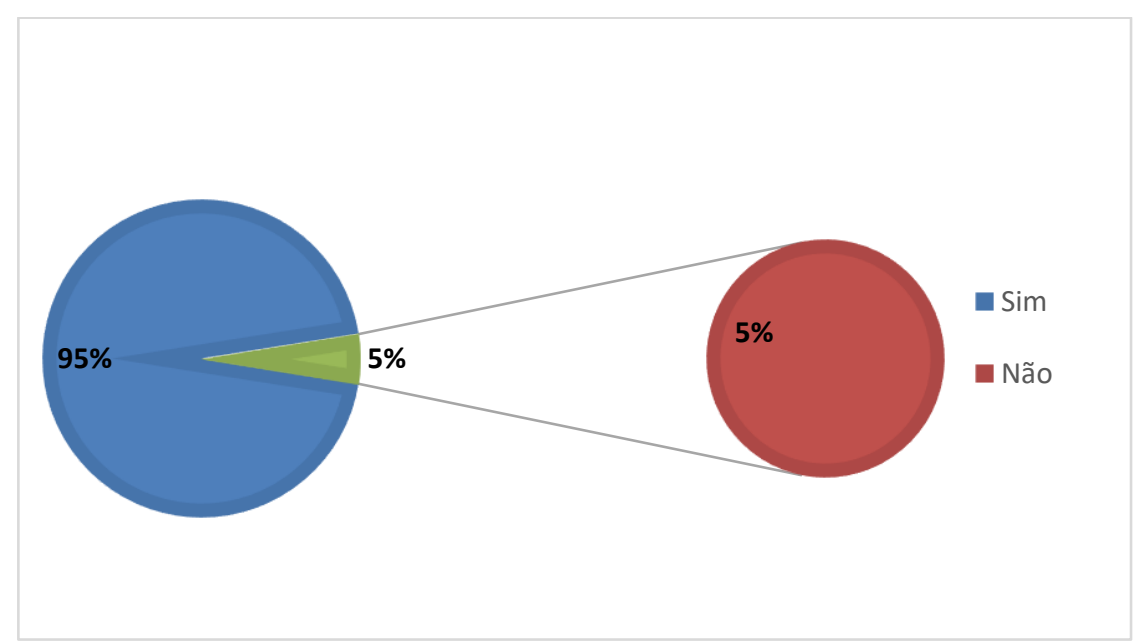

AUTORES (2016)

\subsection{Resultados dos inquéritos aos alunos da Escola Ruy Duarte}

Na sequência fez-se os questionamentos aos alunos da Escola Ruy Duarte, para essa franja da população os dados apresentação igualmente em gráficos. A Figura 7 apresenta os 


\section{Revista Científica ANAP Brasil}

ISSN 1984-3240 - Volume 14, número 34, 2021

resultados da questão, relação saneamento e saúde, 23 (57\%) alunos disseram que conhecem a e 17 (43\%) alunos disseram que não conhecem a relação que o saneamento básico desempenha na saúde da comunidade.

Figura 7 - Conhecimento da relação entre saneamento e saúde

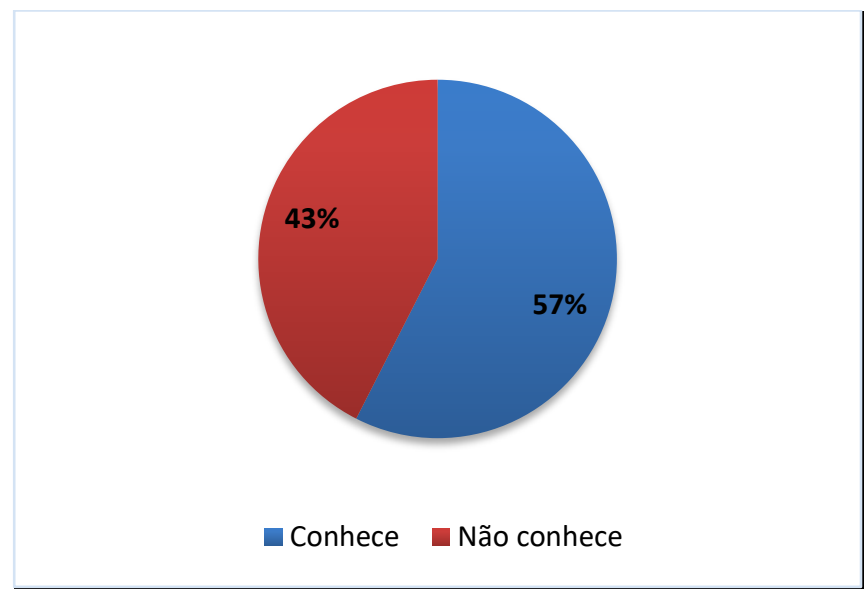

Fonte: AUTORES (2016)

Questionou-se se os alunos já contraíram alguma doença ligada as más condições de saneamento do meio, 23 (57 \%) alunos disseram que sim e 17 (43\%) alunos disseram que não (Figura 8).

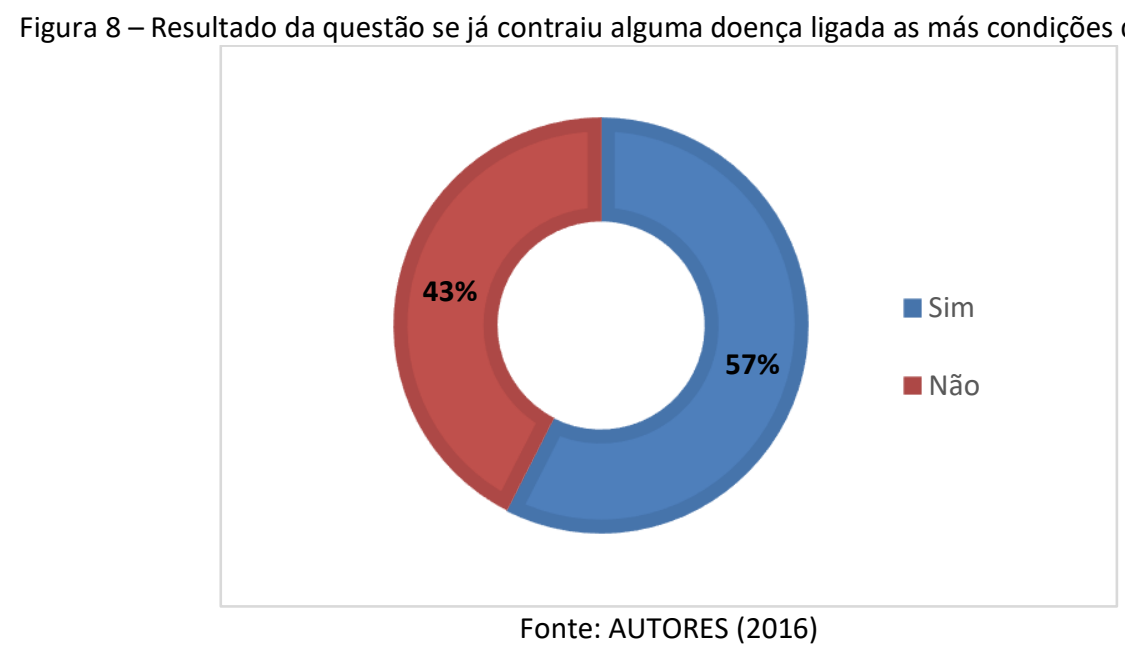

Os alunos no que toca aos conhecimentos e saberes sobre as medidas de prevenção, as doenças ligas as más condições de saneamento básico, houve um equilíbrio nas respostas como se observa na Figura 9, que 20 (50\%) alunos disseram que sim e igualmente 20 (50\%) alunos disseram que não. 


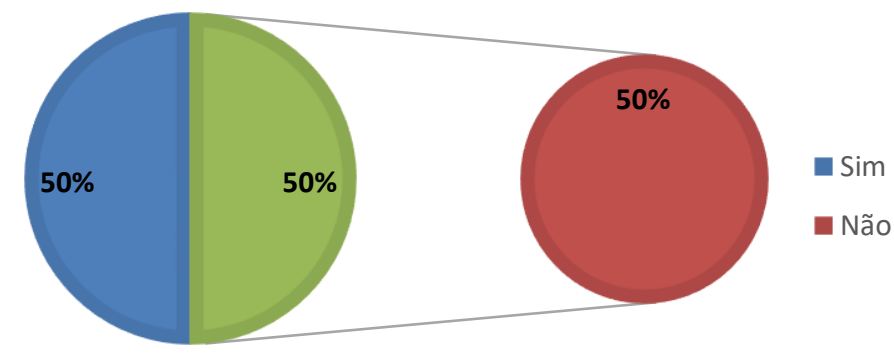

AUTORES (2016)

Fazendo um analise comparativa dos resultados das questões aplicadas a população e aos alunos da Escola Ruy Duarte concluimos: a maioria demonstraram ter conhecimentos sobre a relação do saneamento básico com a e saúde das comunidades e sobre as medidas preventivas, por outro lado, a maioria também disse que sim, já contraíram alguma das doenças ligadas as más condições do saneamento básico.

\subsection{Resultados da entrevista ao Diretor da Escola Ruy Duarte}

- A Escola Contribui para a educação sanitária dos alunos, para que os mesmos adoptem padrões de comportamentos, conforme as normas de higiene? R: Sim.

- A Escola realiza reuniões, palestras ou outros acerca da higiene e doenças causadas por falta dela? R: Sim

- A Escola possui um projeto que visa a melhoria das condições de higiene e saneamento básico da área? Sim.

\subsection{Resultados da entrevista ao Diretor do Centro de Saúde}

- Qual doença apresenta maior número de casos n o período compreendido entre o ano 2012 à 2015? R: A malária

- Qual é a faixa etária mais afetada pelas doenças? R: elementos dos 15 aos 50 anos idade.

- Qual é o gênero mais afetado por essas enfermidades? R: $O$ gênero mais afetado é o feminino. Pelo simples fato de serem as mulheres que mais procuram a nossa unidade hospitalar.

- Os profissionais do centro realizam reuniões, palestras ou outros acerca da higiene e doenças causadas por falta dela? R: Sim.

- O centro contribui para a educação sanitária da população, para que a mesma adopte padrões de comportamentos, conforme as normas de higiene? R: Sim.

Em seguida apresentamos dados recolhidos no centro de saúde referentes as principais doenças relacionadas com as más condições de higiene e saneamento básico da comunidade. A malária foi a doenças com maior ocorrência com destaque aos anos de 2013 e 


\section{Revista Científica ANAP Brasil}

ISSN 1984-3240 - Volume 14, número 34, 2021

2015 com 2.247 e 1.684 casos respetivamente. Tabela 2 ilustra as principais doenças registradas no centro, no período de 2012 a 2015 com um total de 9.844 casos registrados.

Tabela 2 - Doenças relacionadas com o deficiente saneamento básico registradas no Centro de Saúde 2012 a 2015

\begin{tabular}{|l|c|c|c|c|c|}
\hline \multicolumn{1}{|c|}{ Doenças } & Registros de 2012 & Registros de 2013 & Registros de 2014 & Registros de 2015 & Total \\
\hline Malária & 1.893 & 2.247 & 1.345 & 1.684 & 7.169 \\
\hline Febre tifóide & 133 & 200 & 120 & 189 & 642 \\
\hline $\begin{array}{l}\text { Doenças } \\
\text { diarreicas agudas }\end{array}$ & 305 & 559 & 320 & 284 & 1.468 \\
\hline Amebiase & 82 & 222 & 52 & 92 & 448 \\
\hline Infeç̧ões na pele & 14 & 33 & 28 & 42 & 117 \\
\hline \multicolumn{1}{c|}{ Total } & 2.427 & 3.261 & 1.865 & 2.291 & 9.844 \\
\hline
\end{tabular}

Fonte: Dados do Centro de Saúde, 2016.

Em correspondência com a questão "O centro tem registado casos de internamento devido a doenças causadas pela falta de higiene e saneamento básico?", na Tabela 3 ilustra-se os casos de internados devido a doenças causadas pela deficiência de higiene e saneamento básico registradas no Centro de Saúde Eucaliptos no período compreendido entre o ano de 2012 a 2015.

Tabela 3 - Internados devido a doenças relacionadas a deficiência de Higiene e saneamento 2012 a 2015

\begin{tabular}{|c|c|c|}
\hline Anos & Número de internados & Total \\
\hline 2012 & 66 & \multirow{2}{*}{284} \\
\hline 2013 & 84 \\
\hline 2014 & 94 & \\
\hline 2015 & 40 & \\
\hline
\end{tabular}

Fonte: Dados do Centro de Saúde, 2016.

\subsection{Resultados das Observações}

A Figura 10 e 11 ilustram as condições de insalubres em que vive a população do bairro dos Eucaliptos próxima ao Centro de Saúde, lixeira localizada a menos de 20 metros da instalação sanitária e escolar. Na Figura 10, imagem A, observa-se acumulo de lixo no bairro (maior lixeira do bairro) e queimadas provocando poluição do ar, imagem B, crianças brincando no lixão. 


\section{Revista Científica ANAP Brasil}

ISSN 1984-3240 - Volume 14, número 34, 2021

Figura 10 - Condições insalubres em que vive a população próxima ao Centro de Saúde Eucaliptos

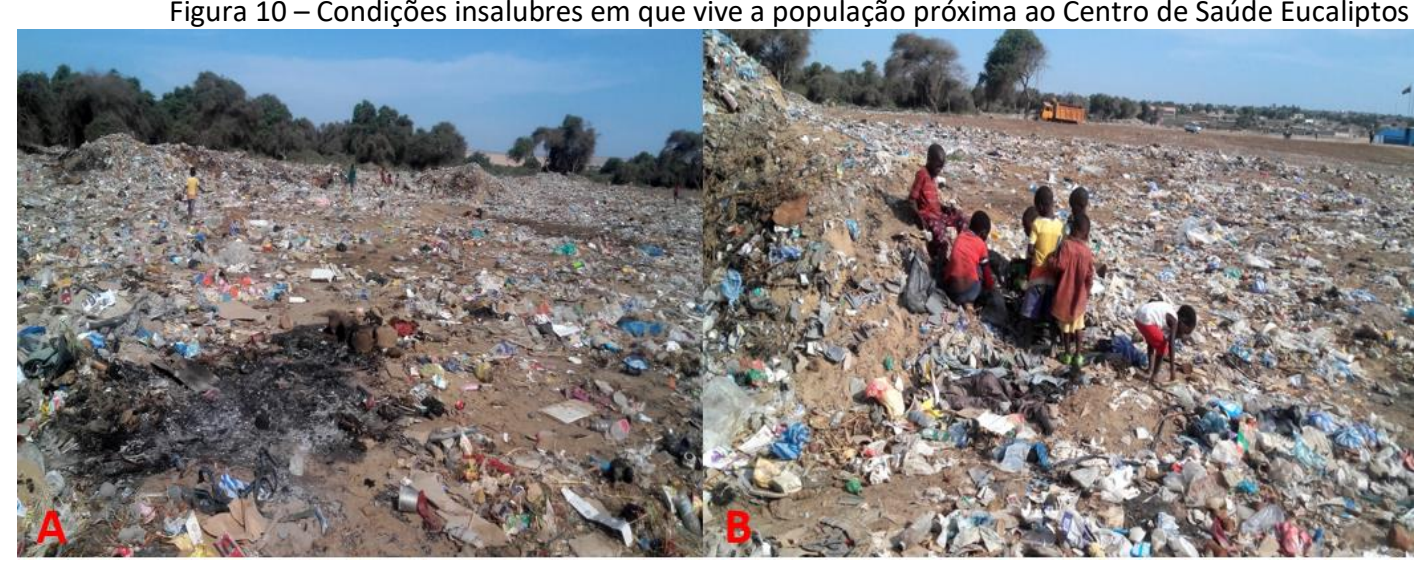

Fonte: AUTORES (2016)

Quanto ao abastecimento de água faz-se o uso de água de tanques abastecidas por cisternas, aberturas de poço, água de cacimbas (Figura $11 \mathrm{~A}$ ), no que toca ao esgoto sanitário a população recorre a fossas sépticas, deposito de água de lavagem domésticas e ligações precária dos banheiros despejadas nas ruas (Figura $11 \mathrm{~B}$ ).

Figura 11 - Condições de saneamento do bairro. A) poço público em péssimo estado de conservação, usado para extração de água de consumo da população. B) esgoto a céu aberto defronte ao portão de uma residência

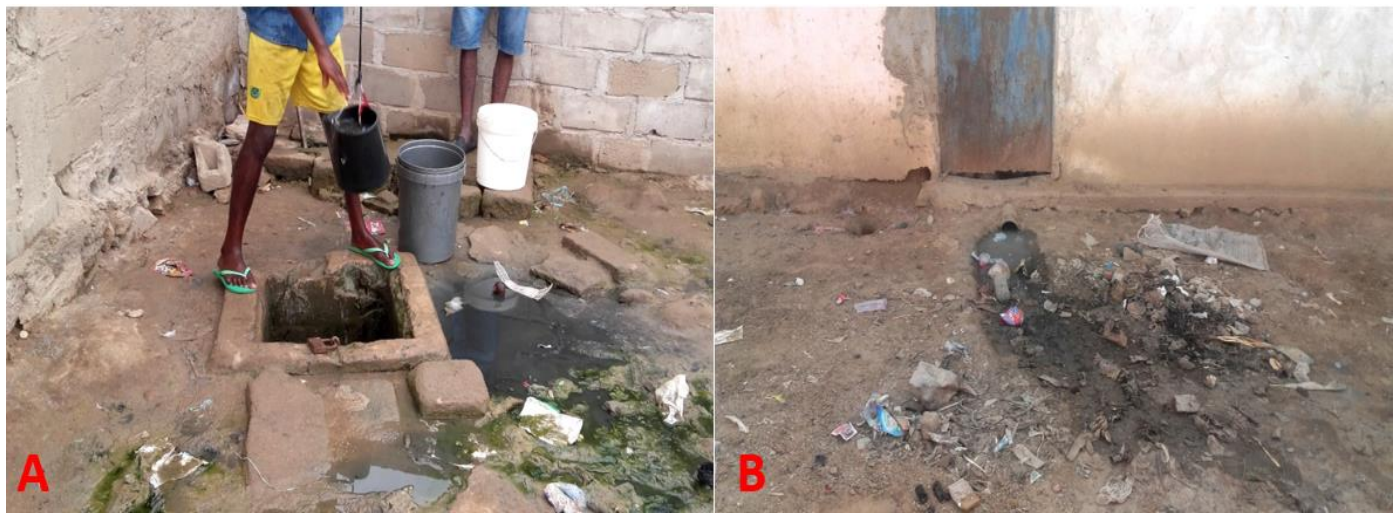

Fonte: AUTORES (2016)

A referida lixeira serve de ponto de deposição de resíduos por parta da população do bairro dos Eucaliptos, da população do bairro Forte Santa Rita e de algumas oficinas e empresas. A população que vive nas imediações do Centro de Saúde Eucaliptos (grupo focal) é a mais afetada pelas deficiências de higiene e Saneamento Básico.

3.7 Propostas de medidas para o melhoramento das condições ambientais e de saúde pública da população do bairro dos Eucaliptos

Para se prevenir a insalubridade no bairro Eucaliptos deve se adotar as seguintes medidas: 


\section{Revista Científica ANAP Brasil}

ISSN 1984-3240 - Volume 14, número 34, 2021

$\checkmark$ Implementar os equipamentos de saneamento do meio: sistema de coleta e deposição adequada de resíduos, limpeza pública das vias, rede de esgoto, aumento da rede pública de água, para se evitar o uso de água de cacimbas e água contaminadas.

$\checkmark$ Manter a higiene pessoal e das moradias.

$\checkmark$ Educar para a saúde a comunidade, para adição de padrões de comportamentais, conforme as normas de higiene e saúde. Sensibilizando a mesma a combater os insetos (moscas, mosquitos, baratas, etc.) transmissores de doenças e eliminar situações que possam favorecer proliferação dos mesmos, desinfectar a água para o consumo.

$\checkmark$ Controle das crianças para que não frequentem as lixeiras.

\section{DISCUSSÃO}

Autores como Teixeira et al., (2009); Ribeiro; Rooke (2010) Carvalho; Adolfo (2012) afirmaram que muitas doenças poderiam ser evitadas através do saneamento básico adequado. Noronha, (2007) e Ribeiro; Rooke (2010); consideram que a má disposição dos resíduos pode influenciar na qualidade do meio ambiente e na saúde do homem. Enquanto que Jacinto (2012); Almeida (2017) usaram da mesma metodologia e tiveram resultados semelhantes; os autores admitem que há relação causa efeito, ou seja, o saneamento pode diminuir certas doenças.

Os resultados demonstraram que a exposição do lixo e esgoto a céu aberto, queimadas descontroladas, consumo de água não tratadas tem causado problemas de saúde nas comunidades, como se pode observar nos registros do centro de saúde. A revisão bibliografia, os inquéritos, a observação e o levantamento fotográfico foram suficientes para o alcance dos objetivos da pesquisa. Para isso, as propostas seguiram orientações da universalização do saneamento básico: Decreto Presidencial n. 196/12 de 30 de agosto, Plano Estratégico para Gestão de Resíduos Urbanos; Despacho presidencial no 262/10, Plano Nacional de Saúde.

\section{CONCLUSÕES}

O saneamento básico manifesta-se como elemento fundamental para o bem estar das pessoas, principalmente para a saúde coletiva. A fraca cobertura de rede de esgoto, abastecimento de água, deposição adequada dos resíduos tem proporcionado o aumento de doenças na referida localidade, como constam dos registros do centro de saúde local, os entrevistados reconhecem a relação do saneamento básico com impacto a saúde comunitária, bem como a necessidade das medidas preventivas para melhoria da qualidade de vida.

\section{AGRADECIMENTOS}

Os autores agradecem as instituições: Instituto Nacional de Bolsas de Estudo (INAGBE) Escola Superior Politécnica do Namibe da Universidade Mandume ya Ndemufayo (ESPtN, UMN) e a Faculdade de Engenharia de Bauru da Universidade Estadual Paulista "Júlio de Mesquita Filho" (FEB, UNESP). 


\section{Revista Científica ANAP Brasil}

ISSN 1984-3240 - Volume 14, número 34, 2021

\section{REFERÊNCIAS}

ALMEIDA, A. R. V. Problemática da gestão dos resíduos sólidos urbanos em Angola. Estudo de caso: província da Huíla Município do Lubango. Dissertação (Mestrado em Recursos Naturais). Faculdade de Ciências Sociais e Humandas da Universidade Nova de Lisboa, Portugal. Lisboa. 2017.

ANGOLA. Decreto Presidencial n. 196/12 de 30 de Agosto de 2012, Plano Estratégico para Gestão de Resíduos Urbanos. Luanda. 2012.

ANGOLA. Decreto Presidencial n.o 190/12 de 24 de agosto de 2012, Regulamento da Gestão dos Resíduos. Luanda. 2012.

ANGOLA. Despacho no 262/10 de 24 de novembro - Plano Nacional da Saúde. Diário da República, I série n. 222. Luanda. 2010.

ANGOLA. Relatório do Estado Geral do Ambiente em Angola. Programa de Investimento Ambiental. Ministério do Urbanismo e Ambiente de Angola. Luanda. 2006. Disponível em: http://www2.ecolex.org. Acesso em: 19 Agost. 2017.

BANCO MUNDIAL. Água e Saneamento em Áreas Rurais e Urbanas. Fonte: Adaptado do Banco Mundial (WB). 2005. Disponível em: http://www.kunenerak.org/. Acesso em 20 Mai. 2015.

CARVALHO, Sonia Aparecida de; ADOLFO, Luis Gonzaga da Silva. O direito fundamental ao saneamento básico como garantia do mínimo existencial social e ambiental. 2012. Revista Brasileira de Direito, IMED, Vol. 8, № 2, jul-dez 2012. Disponível em: https://dialnet.unirioja.es/descarga/articulo/5120195.pdf. Acesso em: 11 Nov. 2020.

Council for International Organizations for Medical Sciences (CIOMS). International Ethical Guidelines for Biomedical Research Involving Human Subjects. Geneva. 2002. Disponível em:

http://www.cioms.ch/publications/layout_guide2002.pdf. Acesso em: 10 Jun. 2016.

DIEHL, A. A.; E TATIM, D. C. Pesquisa em ciências sociais aplicadas: métodos e técnicas. São Paulo. 2004.

GALVÃO JUNIOR, A. C. Desafios para a universalização dos serviços de água e esgoto no Brasil. In Rev Panam Salud Publica. (2009). 2009; 25(6):548-56. Brasil. Disponível em:

http://www.scielosp.org/scielo.php?script=sci_arttext\&pid=S1020-49892009000600012. Acesso em: 14 Jan. 2016.

INSTITUTO NACIONAL DE ESTATÍSTICA (Censo 2014). Resultados Definitivos do Recenseamento Geral da População e da Habitação em Angola. Luanda. 2014.

JACINTO, Monica Maria Pires Lobo. A problemática da água em Angola (1975-2010): caso de estudo - Luanda. (Dissertação de Mestrado). Faculdade de Ciências Sociais e Humanas da Universidade Nova de Lisboa. Lisboa. 2012. Disponível em: https://run.unl.pt/handle/10362/9220. Acesso em: 14 Jan. 2016.

MOTA, F. S. B. Conhecimento para promoção do saneamento, saúde e ambiente. Brasil. 2005.

NORONHA, I. O. Percepção e Comportamento Sócio ambiental: a problemática dos resíduos sólidos urbanos. Revista Académica. 2007.

ORGANIZAÇÃO MUNDIAL DA SAÚDE. Conferência regional FAO/OMS sobre Segurança Alimentar para África Harare, Zimbabwe. 2005.

RIBEIRO, J. W.; ROOKE, J. M. S. Saneamento Básico e sua relação com o Meio Ambiente e a Saúde Pública. (Especialista em Análise Ambiental). Faculdade de Engenharia da Juiz de Fora. Juiz de Fora. 2010.

TEIXEIRA, Júlio César; OLIVEIRA, Guilherme Soares de; VIALI, Amanda de Mello; Samuel Soares MUNIZ. Estudo do impacto das deficiências de saneamento básico sobre a saúde pública no Brasil no período de 2001 a 2009 . Juiz de Fora. 2014. Eng Sanit Ambient | v.19 n.1 | jan/mar 2014 | 87-96. Disponível em:

https://www.scielo.br/j/esa/a/phssQJJDhpFtNjB7dLtwW4b/?format=pdf\&lang=pt. Acesso em: 01 Jan 2017. 